\title{
Study on dosage range evaluation opioid analgesic for breakthrough pain in cancer patients: a retrospective study
}

\author{
Mahardian Rahmadi ${ }^{1,2}$, Ulya Madina ${ }^{3}$, Iwan Sulianto ${ }^{4}$, Elfri Padolo ${ }^{5}$, Chrismawan Ardianto ${ }^{1}$, \\ Dinda M. N. Ratri ${ }^{1,2}$, Agus A. Fauzi ${ }^{4,6}$, Suharjono $^{1}$
}

${ }^{1}$ Clinical Pharmacy Department, Faculty of Pharmacy, Universitas Airlangga, Surabaya, East Java, Indonesia; ${ }^{2}$ Department of Pharmacy, Universitas Airlangga Hospital, Surabaya, East Java, Indonesia; ${ }^{3}$ Faculty of Pharmacy, Universitas Airlangga, Surabaya, East Java, Indonesia; ${ }^{4}$ Palliative Care and Relieved Pain Installation, ${ }^{5}$ Pharmacy Installation, Dr. Soetomo Hospital, Surabaya, East Java, Indonesia; ${ }^{6}$ Faculty of Medicine, Universitas Airlangga, Surabaya, East Java, Indonesia

Contributions: (I) Conception and design: M Rahmadi, I Sulianto, E Padolo; (II) Administrative support: I Sulianto, E Padolo, AA Fauzi, S Suharjono; (III) Provision of study materials or patients: I Sulianto, E Padolo; (IV) Collection and assembly of data: U Madina; (V) Data analysis and interpretation: M Rahmadi, U Madina, C Ardianto, DMN Ratri; (VI) Manuscript writing: All authors; (VII) Final approval of manuscript: All authors.

Correspondence to: Mahardian Rahmadi. Clinical Pharmacy Department, Faculty of Pharmacy, Universitas Airlangga, Surabaya, East Java 60115, Indonesia. Email: mahardianr@ff.unair.ac.id.

Background: Breakthrough pain is an exacerbation of pain occurring in patients with chronic pain who receive opioid therapy every day. Breakthrough pain has not been routinely recognized, evaluated and treated. This study aimed to analyze the utilization of opiates analgesics, including dose regimentation, frequency of use, and the actual adverse effects in cancer patients with breakthrough pain.

Methods: Data were collected by the retrospective method in the period from January to December 2017. Patients involved received opioids around the clock for treating background pain and rescue medication for treating breakthrough pain. The percentage of the rescue medication dose was calculated based on the total daily opioid dose to treat background pain. Descriptive analysis was used.

Results: From 335 visits, there were 334 of patient visit where the patient received immediate-release morphine as a rescue medication with a dose percentage between $6.67-60 \%$, and 1 visit where the patient received codeine with a dose percentage of $16.67 \%$. Of 335 visits, 233 patient visits received the right proportion of opioid rescue medication doses, while 102 patient visits received a greater dose proportion than the recommended dose of 5-20\%.

Conclusions: Immediate-release morphine is the most commonly prescribed analgesic to treat breakthrough pain and used at $6.67-60 \%$ of daily dose with the frequency of use between 2 to 6 times a day. There were 189 (56.42\%) patient visits when the patient experienced the adverse effects of the opioid. The identified actual adverse effects are constipation, nausea, and vomiting.

Keywords: Breakthrough pain; cancer pain; opioid; morphine; dose

Submitted Feb 27, 2020. Accepted for publication Aug 31, 2020.

doi: $10.21037 /$ apm-20-492

View this article at: http://dx.doi.org/10.21037/apm-20-492

\footnotetext{
$\wedge$ ORCID: 0000-0001-6493-3561.
} 


\section{Introduction}

Breakthrough pain (BP) develops from chronic pain. Symptoms of exacerbation came from patients using daily opioid medication. Data from an international survey shows that $65 \%$ of cancer patients have BP. In addition, the variability of $\mathrm{BP}$ prevalence is high in several countries (1). Even though BP can occur several times in 24 hours, the trigger could unpredictable for cancer patients $(2,3)$. This may be caused by the patient's ignorance of cancer pain (4). Opioid and nonsteroidal anti-inflammatory drugs (NSAIDs) are usually chosen for cancer pain management $(2,5)$. Nowadays, a short-acting opioid is widely used for BP control (6). This therapy also needs adequate assessing and monitoring. Unfortunately, identification, evaluation and prescription for BP are still poorly understood (1). The objective of this study was to evaluate the use of opioid, opioid dose, and the actual adverse effect. We present the following article in accordance with the STROBE reporting checklist (available at http://dx.doi. org/10.21037/apm-20-492).

\section{Methods}

This was a retrospective observational study on the visits of patients with cancer at the Palliative Care and Relieved Pain Outpatient Clinic at tertiary care teaching hospital, Dr. Soetomo Hospital in Surabaya. The study was conducted in accordance with the Declaration of Helsinki (as revised in 2013) and was approved by the local Ethics Committee of the Dr. Soetomo Hospital with serial number 0033/ KEPK/II/2018 and individual consent for this retrospective analysis was waived. Data were collected between January and December 2017.

\section{Participant}

Patient with cancer diagnosis, undergoing opioid therapy and experiencing BP were included. Patients were excluded from the study according to the following exclusion criteria: hypersensitivity to an opioid. Patient characteristic data recorded were sex, gender, final diagnosis and Karnofsky scale. This study reviewed opioid therapy for BP in 335 patient visits. The therapy profile was taken from the secondary data medical record. Pain intensity used a Numerical Rating Scale (NRS) with a Visual Analogue Scale (VAS) method adapted from the medical record. Pain intensity was considered as a mean pain scale over the last week. Patients with $\mathrm{BP}$ have received morphine immediate release (MOIR) tablets or crushed morphine sustained-release tablets (MST) because of national outof-stock conditions. The percentage of opioid dose for $\mathrm{BP}$ was calculated by dividing the opioid dose for BP to the total daily opioid dose in a morphine dose conversion. The appropriate dosage range for $\mathrm{BP}$ treatment is between $5-20 \%$ of total daily opioid dose consumed $(1,7)$.

\section{Data analysis}

A descriptive analysis was used to evaluate the pain scales, patient's opioid therapy, appropriate dose range, other analgesics usage and adverse drug reactions from opioid use. Missing data were shown in the table.

\section{Results}

\section{Participant flow and baseline data}

Around $11 \%$ of 861 patients visited the Palliative Care Outpatient Clinic at Dr. Soetomo Hospital were treated with an opioid for BP. Those patients made 726 visits between January and December 2017. About 46\% of the visits was followed by an opioid regimentation for BP rescue medication. From the total population, $59.41 \%$ were woman. Patients aged $45-64$ years were $51.49 \%$ of the studied population, and around one-third were $20-44$ years old. The smallest portion of patients $(6 \%)$ were aged $65-$ 84 years. The diagnoses were both solid and haematology cancer. Diagnoses were cervical cancer (30.69\%), nasopharyngeal cancer $(11.88 \%)$, acute lymphoblastic leukaemia (ALL) (7.92\%), breast cancer (5.94\%) and rectal cancer $(3.96 \%)$. On the Karnofsky scale, $85.15 \%$ of the patients scored $50-70 \%, 10.89 \%$ scored $80-100 \%, 2.97 \%$ were unrecorded, and one patient was $0-40 \%$ (Table 1).

\section{Outcomes}

Based on the medical records, patients with moderate pain were $55.52 \%$ of the population; severe pain, $29.25 \%$; mild pain, $14.03 \%$; and not recorded, $1.19 \%$ as shown in Table 2. Type of opioid was consumed: MOIR, MST, codeine, fentanyl patch, and a combination of MST and fentanyl patch. Opioid dose and frequency are displayed in Table 3. This table shows that the most commonly used types of opioids are MST $54.33 \%(\mathrm{n}=182)$, followed by MOIR 23.28\% ( $\mathrm{n}=78)$, and fentanyl $20.60 \%(\mathrm{n}=69)$. Cancer 
Table 1 Characteristics of patients

\begin{tabular}{|c|c|}
\hline Characteristics & N (\%) \\
\hline \multicolumn{2}{|l|}{ Sex } \\
\hline Female & $60(59.4)$ \\
\hline Male & $41(40.6)$ \\
\hline \multicolumn{2}{|l|}{ Ages (years) ${ }^{\dagger}$} \\
\hline$<20$ & $11(10.9)$ \\
\hline $20-44$ & $32(31.7)$ \\
\hline $45-64$ & $52(51.5)$ \\
\hline $65-84$ & $6(5.9)$ \\
\hline \multicolumn{2}{|l|}{ Final diagnosis } \\
\hline Cervix cancer & $31(30.7)$ \\
\hline Nasopharyngeal cancer & $12(11.9)$ \\
\hline ALL & $8(7.9)$ \\
\hline Breast cancer & $6(5.9)$ \\
\hline Rectal cancer & $4(4.0)$ \\
\hline Tongue cancer & $4(4.0)$ \\
\hline Bladder cancer & $3(3.0)$ \\
\hline Osteosarcoma & $3(3.0)$ \\
\hline Lung cancer & $3(3.0)$ \\
\hline Ovarian cancer & $2(2.0)$ \\
\hline Endometrial cancer & $2(2.0)$ \\
\hline Prostate cancer & $2(2.0)$ \\
\hline LNH & $2(2.0)$ \\
\hline Pancreatic head cancer & $2(2.0)$ \\
\hline Vulvar cancer & $1(1.0)$ \\
\hline Testicular cancer & $1(1.0)$ \\
\hline Colon cancer & $1(1.0)$ \\
\hline Thyroid cancer & $1(1.0)$ \\
\hline Lymphoma cancer & $1(1.0)$ \\
\hline Caecum cancer & $1(1.0)$ \\
\hline Sinonasal cancer & $1(1.0)$ \\
\hline Renal cancer & $1(1.0)$ \\
\hline Others $^{\ddagger}$ & $9(8.9)$ \\
\hline \multicolumn{2}{|l|}{ Karnofsky scale } \\
\hline $0-40$ & $1(1.0)$ \\
\hline $50-70$ & $86(85.1)$ \\
\hline
\end{tabular}

Table 1 (continued)
Table 1 (continued)

\begin{tabular}{lc}
\hline Characteristics & $\mathrm{N}(\%)$ \\
\hline $80-100$ & $11(10.9)$ \\
Not recorded & $3.0)$ \\
\hline${ }^{\dagger}$, age range distribution based on modification of the National \\
Cancer Institute guidelines $(8) ;{ }^{\ddagger}$, others: malignant spindle \\
mesenchymal tumor reg clavicula, malignant cell bone, soft \\
tissue tumor, proximal femoral region, malignant spindle cell \\
tumor, chronic myeloid leukemia with hyperleukocytosis, \\
cerebral metastatic neoplasm, salivary duct cancer metastases \\
to the bone and cerebri, conjunctival tumor dd non-Hodgkin \\
lymphoma, upper tract urothelial carcinoma, and hepatoma; \\
$\S$, Karnofsky performance status scale at first visit. ALL, acute \\
lymphoblastic leukaemia; LNH, lymphoma non-Hodgkin.
\end{tabular}

patients received BP treatment with an opioid in 335 visits. There were only 5 visits with combination therapy. Patients were treated with MOIR in $92.84 \%(n=311)$ of the visits. Some patients received crushed MST $6.87 \%(n=23)$ due to a national out-of-stock condition, and one patient received codeine on one visit. The percentage of rescue medication for BP with MOIR was from $6.67 \%$ to $60 \%$ of the total daily opioid dose. Among them, between $10 \%$ and $33.33 \%$ were given crushed MST. Also, the patient who received codeine for BP was given $16.67 \%$ of the total daily opioid dose. From the result described above, $56.42 \%(n=189)$ of patients received an appropriate dosage range, and $43.58 \%$ $(n=146)$ received a dose higher than $20 \%$ of their regular daily intake.

Patients admitted to non-opioid analgesic drugs and adjuvant analgesics therapy for relief of around-theclock cancer pain are documented in Table 4. Paracetamol was used less than 300 times. It was the most used nonopioid analgesic, followed by meloxicam, at 87 times. Amitriptyline was used more than 300 times as an adjuvant analgesic, followed by gabapentin, at 51 times. This study also provides information about the actual adverse effects of opioid therapy. Constipation, nausea, and vomiting were recorded as adverse effects in 120,95 , and 40 visits, respectively.

\section{Discussion}

In fact, the mechanism of BP episodes is not fully understood. BP pain due to the release of nociceptive factors, such as nerve growth factor (NGF) from sensory and sympathetic neurons that have abnormalities (12). The 
Table 2 Pain intensity patients every visit

\begin{tabular}{lcc}
\hline Pain intensity $^{\dagger}$ & Subject $(\mathrm{n}=335)$ & Percentage (\%) \\
\hline Mild [1-3] & 47 & 14.03 \\
Moderate [4-6] & 186 & 55.52 \\
Severe [7-10] & 98 & 29.25 \\
Not recorded & 4 & 1.19 \\
\hline
\end{tabular}

${ }^{\dagger}$, pain intensity according to the National Institute of Health (9). prevalence of BP in this study was smaller than in other studies, possibly because of the inclusion and exclusion criteria, and the method of sampling was different (13). Additionally, based on this study less than $50 \%$ of cancer patient visits with BP took an opioid for BP. This may be due to pain manifestation being poorly recorded in secondary data. There were more female patients than male patients, which is related to the diagnosis. One-third of the

Table 3 Opioid regimen

\begin{tabular}{|c|c|c|c|c|c|}
\hline Type of opioid & Opioid dose & Subject (n) & Opioid dose for BP & $\begin{array}{l}\text { Opioid dose for BP/total } \\
\text { opioid dose/day (\%) }\end{array}$ & $\begin{array}{l}\text { Appropriate dosage } \\
\text { range }^{\dagger \ddagger} \text { (\% sample) }\end{array}$ \\
\hline \multirow[t]{2}{*}{ MOIR } & $2-15$ mg every 6 hours & 22 & $1-10 \mathrm{mg}$ & $12.5-25$ & 72.72 \\
\hline & 3-15 mg every 4 hours & 56 & $1-10 \mathrm{mg}$ & $8.33-25$ & 94.64 \\
\hline MST & $10-30 \mathrm{mg}$ every 12 hours & 181 & $2.5-10 \mathrm{mg}$ & $8.33-50$ & 51.38 \\
\hline Codeine & 40 mg every 4 hours & 1 & 20 mg (codeine $\left.{ }^{\S}\right)$ & 16.67 & 100 \\
\hline \multirow[t]{2}{*}{ MST and fentanyl } & $\begin{array}{c}25 \text { mg every } 12 \text { hours and } \\
12.5 \mu \mathrm{g} / \text { hour every } 72 \text { hours }\end{array}$ & 3 & $10 \mathrm{mg}$ & 13.33 & 100 \\
\hline & $\begin{array}{c}2 \times 15 \mathrm{mg} \text { and } 25 \mu \mathrm{g} / \mathrm{hour} \text { every } \\
72 \text { hours }\end{array}$ & 2 & $10 \mathrm{mg}$ & 12.5 & 100 \\
\hline
\end{tabular}

${ }^{\dagger}$, appropriate dosage range is between $5-20 \%$ based on Cancer Care Ontario (7); ${ }^{\ddagger}$, appropriate dosage range is between $5-20 \%$ based on International Association for the study of Pain (1); ${ }^{\S}$, codeine to morphine dose conversion: 200 mg codeine in 24 hours $~ 30$ mg morphine in 24 hours (10); ", fentanyl to morphine dose conversion: $1 \mu \mathrm{g} /$ hour fentanyl $2 \mathrm{mg}$ morphine in 24 hours (11). BP, breakthrough pain; MOIR, morphine immediate release; MST, morphine sustained release tablet.

Table 4 Non-opioid and adjuvant analgesics profile

\begin{tabular}{|c|c|c|c|}
\hline Analgesics & Drug dose & Route & Subject (n) \\
\hline Paracetamol & $150-500 \mathrm{mg}$ & Oral & 292 \\
\hline Meloxicam & $7.5-15 \mathrm{mg}$ & Oral & 97 \\
\hline Paracetamol + N-acetyl cysteine & $150-500 \mathrm{mg}$ & Oral & 19 \\
\hline Ibuprofen & $200 \mathrm{mg}$ & Oral & 4 \\
\hline Mefenamic acid & $250-500 \mathrm{mg}$ & Oral & 2 \\
\hline \multicolumn{4}{|l|}{ Adjuvant analgesics } \\
\hline Amitriptyline & $12.5-25 \mathrm{mg}$ & Oral & 320 \\
\hline
\end{tabular}


patients were diagnosed with cervical cancer. In a previous study, BP in patients with cancer is not linked to gender and age (14). In this study, patients with moderate and severe pain might have a Karnofsky score under 70 . The level and frequency of BP episodes are reported that affect the daily activity and the ability to work $(15,16)$. From the previous report, most of the patients with a lower-level Karnofsky scale had a higher BP intensity (16). Previous studies demonstrate similar profiles showing that moderate pain is more likely to be associated with BP than mild pain (14).

Another study presents that the most widely used opioid is MST. A previously reported meta-analysis concludes that morphine administration has beneficial effects. This drug reduces the intensity of pain and has a satisfying effect on the patient (17). The present study noted that patients who were opioid-naive with unstable pain were considered for MOIR therapy. Then, if the pain becomes more stable, therapy was replaced with MST. In addition, another study shows the advantage of using MST is to increase compliance (18). This study showed several patients received a MOIR regimen that was lower than the reference (19). The previous reports prove lowdose morphine is effective in reducing pain with high tolerability and quick onset of action (20-22). Our study demonstrated combination opioid therapy was chosen for patients who had uncontrolled pain with one type of opioid. The fentanyl patch and morphine is an alternative combination therapy in a current clinical situation in this study. The incidence of pain relief in combination therapy is high in a previous study (23), even though this may increase the rate of adverse drug reactions. Our study showed rapid-onset opioid is prescribed for BP pain (1). Also, this study highlighted a high percentage dose of morphine for BP should have required reassessment on the number of episodes of $\mathrm{BP}$, the relation between $\mathrm{BP}$ and baseline pain, BP intensity, onset, and duration of BP.

Besides opioid analgesics, other analgesics were given to the cancer patients in the present study. Many patients receive paracetamol for analgesia in BP. Previous studies indicate that paracetamol is not supported by high-quality evidence to prove its effectiveness. However, paracetamol exhibits favorable safety in gastrointestinal tolerance and still widely used (24-26). Almost all the population in this study received amitriptyline as an adjuvant analgesic. Amitriptyline is a potent adjuvant analgesic in malignant or non-malignant neuropathic pain and significantly reduce the VAS score more than other tricyclic antidepressants (TCA) (27). The interpretation of this study is limited by retrospective design study, incomplete data in the medical records. The study did not address the statistical examination. Therefore, multicenter studies could also be prospectively designed to aggressively assess the effectiveness of BP treatment and adjustment an opioid dose individualize.

\section{Conclusions}

This retrospective study conducted by examining the records of 335 patient visits with BP indicates that the majority of the pain scale is moderate and relieved with morphine therapy. The dose to resolve the $\mathrm{BP}$ ranges from $6.67 \%$ to $60 \%$. Only around $50 \%$ of patients receive an appropriate dose. The data indicate that paracetamol and amitriptyline are the most prescribed non-opioid and adjuvant analgesics. In addition, this study suggests that constipation, nausea, and vomiting are the actual adverse effects induced by the utilization of opioids.

\section{Acknowledgments}

Funding: This research was supported with a financial assistance: Tahir Professorship Program.

\section{Footnote}

Reporting Checklist: The authors have completed the STROBE reporting checklist. Available at http://dx.doi. org/10.21037/apm-20-492

Data Sharing Statement: Available at http://dx.doi. org/10.21037/apm-20-492

Conflicts of Interest: All authors have completed the ICMJE uniform disclosure form (available at http://dx.doi. org/10.21037/apm-20-492). The authors have no conflicts of interest to declare.

Ethical Statement: The authors are accountable for all aspects of the work in ensuring that questions related to the accuracy or integrity of any part of the work are appropriately investigated and resolved. The study was conducted in accordance with the Declaration of Helsinki (as revised in 2013). This research was approved by the local Ethics Committee of the Dr. Soetomo Hospital with serial number 0033/KEPK/II/2018 and individual consent for this retrospective analysis was waived. 
Open Access Statement: This is an Open Access article distributed in accordance with the Creative Commons Attribution-NonCommercial-NoDerivs 4.0 International License (CC BY-NC-ND 4.0), which permits the noncommercial replication and distribution of the article with the strict proviso that no changes or edits are made and the original work is properly cited (including links to both the formal publication through the relevant DOI and the license). See: https://creativecommons.org/licenses/by-nc-nd/4.0/.

\section{References}

1. Mercadante S, Arcuri E. Breakthrough Pain in Cancer Patients. Pain: Clinical Updates 2016;14:1-4.

2. Zeppetella G. Breakthrough pain in cancer patients. Clin Oncol (R Coll Radiol) 2011;23:393-8.

3. Winiarczyk K, Knetki-Wróblewska M. Breakthrough pain in cancer patients. Oncol Clin Pract 2016;12:1-6.

4. Baker TA, O'Connor ML, Krok JL. Experience and knowledge of pain management in patients receiving outpatient cancer treatment: What do older adult really know about their cancer pain? Pain Med 2014;15:52-60.

5. Mercadante S, Villari P. An Italian survey on the attitudes in treating breakthrough cancer pain in hospice. Support Care Cancer 2011;19:979-83.

6. Rudowska J. Management of breakthrough pain due to cancer. Contemp Oncol (Pozn) 2012;16:498-501.

7. Sawhney M, Fletcher GG, Rice J, et al. Guidelines on Management of Pain in Cancer and/or Palliative Care. ES 18-4. Toronto: Cancer Care Ontario, 2017:1-88.

8. NCI editors. Age and Cancer Risk was originally published by the National Cancer Institute [Internet]. Rockville: National Cancer Institute; 2015 [cited 2019 Des 20]. Available online: https://www.cancer.gov/about-cancer/ causes-prevention/risk/age

9. McCaffery M, Beebe A, Latham J, et al. Pain: Clinical Manual for Nursing Practice. Intensity Instruments. Baltimore: Mosby, 1997.

10. Schneider C, Yale SH, Larson M. Principles of Pain Management. Clin Med Res 2003;1:337-40.

11. McPherson ML. editor. Demystifying Opioid Conversion Calculations: A Guide for Effective Dosing. Bethesda: American Society of Health-System Pharmacists; 2009.

12. Hansen RR, Nasser A, Falk S, et al. Chronic administration of the selective $\mathrm{P} 2 \mathrm{X} 3, \mathrm{P} 2 \mathrm{X} 2 / 3$ receptor antagonist, A-317491, transiently attenuates cancer-induced bone pain in mice. Eur J Pharmacol 2012;688:27-34.

13. Zeppetella G, Ribeiro MDC. Pharmacotherapy of cancer- related episodic pain. Expert Opin Pharmacother 2003;4:493-502.

14. Deandrea S, Corli O, Consonni D, et al. Prevalence of Breakthrough Cancer Pain: A Systematic Review and a Pooled Analysis of Published Literature. J Pain Symptom Manage 2014;47:57-76.

15. Hwang SS, Chang VT, Kasimis B. Cancer breakthrough pain characteristics and responses to treatment at a VA medical center. Pain 2003;101:55-64.

16. Mercadante S, Marchetti P, Cuomo A, et al. Factors Influencing the Clinical Presentation of Breakthrough Pain in Cancer Patients. Cancers (Basel) 2018;10:175.

17. Wiffen PJ, Wee B, Moore RA. Oral morphine for cancer pain. Cochrane Database Syst Rev 2013;(7):CD003868.

18. Brown J, Setnik B, Lee K, et al. Assessment, stratification, and monitoring of the risk for prescription opioid misuse and abuse in the primary care setting. J Opioid Manag 2011;7:467-83.

19. Lacy CF, Armstrong LL, Goldman MP, et al. Drug Information Handbook. 17th edition. Ohio: Lexi-Comp, 2009.

20. Ripamonti CI, Campa T, Fagnoni E, et al. Normal-release oral morphine starting dose in cancer patients with pain. Clin J Pain 2009;25:386-90.

21. Mercadante S, Porzio G, Ferrera P, et al. Low Morphine Doses in Opioid-Naive Cancer Patients with Pain. J Pain Symptom Manage 2006;31:242-7.

22. Bandieri E, Romero M, Ripamonti CI, et al. Randomized Trial of Low-Dose Morphine Versus Weak Opioids in Moderate Cancer Pain. J Clin Oncol 2016;34:436-42.

23. Kim HJ, Kim YS, Park SH. Opioid rotation versus combination for cancer patients with chronic uncontrolled pain: a randomized study. BMC Palliat Care 2015;14:41.

24. Axelsson B, Stellborn P, Ström G. Analgesic effect of paracetamol on cancer related pain in concurrent strong opioid therapy. A prospective clinical study. Acta Oncol 2008;47:891-5.

25. Wiffen PJ, Derry S, Moore RA, et al. Oral paracetamol (acetaminophen) for cancer pain. Cochrane Database Syst Rev 2017;7:CD012637.

26. Cazacu I, Mogosan C, Loghin F. Safety Issue of Current 
Analgesics: An Update. Clujul Med 2015;88:128-36.

27. Mishra S, Bhatnagar S, Goyal GN, et al. A Comparative Efficacy of Amitriptyline, Gabapentin, and Pregabalin in
Neuropathic Cancer Pain: A Prospective Randomized Double-Blind Placebo-Controlled Study. Am J Hosp Palliat Care 2012;29:177-82.

Cite this article as: Rahmadi M, Madina U, Sulianto I, Padolo E, Ardianto C, Ratri DMN, Fauzi AA, Suharjono. Study on dosage range evaluation opioid analgesic for breakthrough pain in cancer patients: a retrospective study. Ann Palliat Med 2021;10(2):1237-1243. doi: 10.21037/apm-20-492 